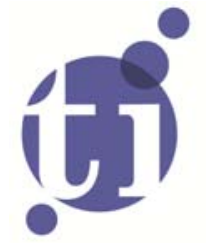

\title{
Cultural Diversity and Cultural Distance as Choice Determinants of Migration Destination
}

Zhiling Wang

Thomas de Graaff

Peter Nijkamp 
Tinbergen Institute is the graduate school and research institute in economics of Erasmus University Rotterdam, the University of Amsterdam and VU University Amsterdam.

More TI discussion papers can be downloaded at http://www.tinbergen.nl

Tinbergen Institute has two locations:

Tinbergen Institute Amsterdam

Gustav Mahlerplein 117

1082 MS Amsterdam

The Netherlands

Tel.: +31(0)205251600

Tinbergen Institute Rotterdam

Burg. Oudlaan 50

3062 PA Rotterdam

The Netherlands

Tel.: +31(0)10 4088900

Fax: $+31(0) 104089031$

Duisenberg school of finance is a collaboration of the Dutch financial sector and universities, with the ambition to support innovative research and offer top quality academic education in core areas of finance.

DSF research papers can be downloaded at: http://www.dsf.nl/

Duisenberg school of finance

Gustav Mahlerplein 117

1082 MS Amsterdam

The Netherlands

Tel.: +31(0)20 5258579 


\title{
Cultural Diversity and Cultural Distance as
}

\section{Choice Determinants of Migration}

\section{Destination*}

\author{
Zhiling Wang ${ }^{1,2}$, Thomas de Graaff ${ }^{2}$, and Peter Nijkamp ${ }^{1,2}$ \\ ${ }^{1}$ Tinbergen Institute, the Netherlands \\ ${ }^{2}$ Department of Spatial Economics, VU University Amsterdam, the Netherlands
}

May 28, 2014

\footnotetext{
${ }^{*}$ Corresponding author: Zhiling Wang. Email: z.wang.vu@gmail.com. Thomas de Graaff and Peter Nijkamp participated in the Migrant Diversity and Regional Disparity in Europe (MIDI-REDIE) project, funded by the NORFACE research programme Migration in Europe-Social, Economic, Cultural and Policy Dynamics. This paper benefited greatly from comments and suggestions made by Wim Bernasco, Joop Hartog, Jacques Poot, Jan Rouwendal, participants at seminars at the Tinbergen Institute, Amsterdam, and at the NORFACE migration conference at UCL, London.
} 


\begin{abstract}
This study analyses the impact of cultural composition on regional attractiveness from the perspective of migrant sorting behaviour. We use an attitudinal survey to quantify cultural distances between natives and immigrants in the area concerned, and estimate the migrants' varying preferences for both cultural diversity and cultural distance. To account for regional unobserved heterogeneity, our econometric analysis employs artificial instrumental variables, as developed by Bayer et al. (2004a). The main conclusions are twofold. On the one hand, cultural diversity increases regional attractiveness. On the other hand, average cultural distance greatly weakens regional attractiveness, even when the presence of network effect is controlled for.
\end{abstract}

Keywords: migration, cultural diversity, cultural distance, destination choice, sorting 


\section{Introduction}

Economic incentives significantly determine migration flows (Borjas et al., 1992; Borjas, 1987; Carrington et al., 1996; Chiswick, 1999). Migrants tend to emigrate to areas with relatively high wages and low moving costs. Apart from economic concerns, immigrants also seem to care about localized social interaction in the receiving areas. Culturallydiversified areas are always found to be self-perpetuating in attracting immigrants (see, e.g., Bakens et al., 2013; Florida, 2002; Ottaviano and Peri, 2005a; Ottaviano and Peri, $2005 b)^{1}$, which implies the importance of compositional concerns in location choice.

It should be noted, however, that cultural diversity only partially accounts for differences in regional or urban ${ }^{2}$ attractiveness. Not only the sizes or shares of cultural groups matter for migrants' destination choices, but also the between-group cultural distances within the area. Consider, for example, the case where: Region 1 is composed of $50 \%$ Dutch and $50 \%$ Germans; region 2 is composed of $50 \%$ Dutch and $50 \%$ Turks. The two regions are not equally attractive to migrants, although they have statistically the same level of cultural diversity. ${ }^{3}$ Therefore, in order to describe the cultural composition of a specific area, it is necessary to use at least two indices: "cultural diversity" and "cultural distance". Cultural diversity describes the compositional profile of diverse or different cultures as opposed to monoculture in a given area. It is often measured as the probability that two randomly selected persons from a given area will not belong to the same ethno-linguistic group (Mauro, 1995), commonly referred to as the fractionalization index. The second concept, cultural distance, describes how dissimilar a culture actually is among these groups. It touches upon the specific cultural traits and characteristics of people in the

\footnotetext{
${ }^{1}$ Other local characteristics and amenities also play significant roles in attracting migrants (Chen and Rosenthal, 2008; Glaeser et al., 2001; Haurin, 1980; Roback, 1982; Rodríguez-Pose and Ketterer, 2012; Scott, 2010), including weather, population density, physical setting, public goods provision, etc.

${ }^{2}$ The words "region", "urban", and "area" are used interchangeably in the following text.

${ }^{3}$ Distinctive compositions of norms, values and beliefs endow the two regions with different compositional amenities. The consequences are shown by Card et al. (2012), who found that compositional concerns are much more important than economic concerns in shaping natives' anti-immigrant attitudes.
} 
area concerned. Similar attitudes and beliefs are usually driven by the collective "mental programming' of people with a similar cultural background (Hofstede et al., 2010), and we therefore measure these by the quantitative differences in attitudinal survey responses between the natives and the immigrants within an area. In brief, cultural diversity is mainly a quantitative measure, while cultural distance is more a qualitative measure. ${ }^{4}$

In this paper we aim to analyse the contribution of cultural composition to regional attractiveness for migrants. We construct a regional index for average cultural distance (using attitudinal responses), and compare its contribution to regional attractiveness with that of an index for regional cultural diversity. From a theoretical perspective, diverse groups of people make an area attractive because of the accompanying diverse consumer amenities and complementarities of skills in various sectors of the economy (Ottaviano and Peri, 2005b), while a substantially large cultural distance between natives and immigrants may create misunderstanding and social conflict, thus making an area unattractive (Caselli and Coleman, 2013). We examine these possible effects by employing an equilibrium sorting model proposed by Bayer et al. (2004a). The bottom line is the following research question: What kind of societal cultural composition do migrants prefer?

Two major assumptions are imposed to validate our analysis. Firstly, we assume that migrants' heterogeneous preferences over regional characteristics and amenities remain relatively constant over time. Namely, the analysis is implemented on a cross-sectional sample from the population of local migrants, who immigrated in different years. This stable preference pattern assumption ensures that a migrant with a specific set of individual characteristics always prefers the same regional characteristics and amenities. It also ensures the study's implications for future migrants' destination choices. The

\footnotetext{
${ }^{4}$ Despite the possible confusion of using "cultural" in both phrases (firstly connoting ethno-linguistic classifications and secondly connoting values and beliefs), we stick to the terminologies in order to be consistent with the literature.
} 
second assumption is freedom of movement: migrants derive utility from living in a certain region and are able to move to that region with the highest utility. This ensures the validity of a discrete choice model. The validity of both assumptions are tested by looking at a subsample of migrants from recent years and a subsample of migrants from the European Union.

Our main findings from this study are twofold. On the one hand, cultural diversity enhances regional or urban attractiveness, thus confirming previous research. On the other hand, a large average cultural distance within an area has a negative impact on regional or urban attractiveness. In other words, even though culturally diverse areas are very attractive to potential migrants, this advantage diminishes if there are substantially large cultural differences between natives and immigrants in the area. This conclusion holds especially for European Union (hereafter EU) migrants, who emigrated from one EU member state to another. ${ }^{5}$ We also find that migrants are more likely to move to regions that are geographically close to their countries of origin and are culturally close to their own cultural backgrounds. However, for a migrant's destination choice, cultural proximity is valued almost three times as much as geographical proximity. Network effect is found to be strong, but has diminished greatly for migrants in recent years. Our results are robust, when we take into account the possible assimilation of migrants, a subset of attitudinal questions, and an alternative way to describe cultural composition.

We contribute to the literature in three ways. Firstly, we address the joint incorporation of cultural diversity and cultural distance in a nested econometric model. To the best of our knowledge, this paper is the first attempt to identify the combined impact of cultural diversity and cultural distance on regional or urban attractiveness. Secondly, the measurement of cultural distance is systematically and operationally explored in this paper, by summarizing the responses from attitudinal survey questions, and then using a

\footnotetext{
${ }^{5}$ Non-EU migrants are those who migrate to the EU from countries outside the EU.
} 
principal component analysis to efficiently construct a new index for regional cultural composition. Thirdly, we employ a new type of instrumental variable in our empirical analysis. Unlike other culturally-related studies, in which historical and geographical variables are often used as instruments, we apply artificial instrumental variables.

The remainder of the paper is organized as follows. Section 2 initiates a brief discussion on cultural diversity and cultural distance. In Section 3, we discuss the sorting model used for our empirical analysis and the endogeneity problem to be tackled. Section 4 describes the data set and the variables, and then Section 5 presents and interprets the estimation results. Section 6 gives the results for different robustness checks, including those that validate our two main assumptions. All are found to be in line with our main findings. The final section provides concluding remarks, and discusses avenues for future research.

\section{Cultural Diversity and Cultural Distance}

Cultural diversity (hereafter denoted as Div) has generated a large literature in the recent decade, as summarized by Alesina and La Ferrara (2005) and Nijkamp and Baycan (2012). It has penetrated gradually into more and more economic issues, such as urban or regional growth and local public goods provision. To operationalize cultural diversity, much of the literature used an index of fractionalization to measure cultural diversity, written as:

$$
\operatorname{Div}_{j}=1-\sum_{i=1} s_{i j}^{2}, \quad i=1, \ldots, I \quad \text { and } j=1, \ldots, J,
$$

where $s_{i j}$ is the share of group $i$ over the total population in a specific region $j$. Div is region-specific, and measures the probability that two randomly selected individuals from 
a given area will not belong to the same group. ${ }^{6}$ In our study, we use this fractionalization index to measure cultural diversity and we classify groups by country of origin. The higher the $D i v_{j}$, the more fragmented into groups the area is.

The second concept, cultural distance, is carefully explored in this study. To quantify cultural distance, we employ the responses to attitudinal survey questions from the European Social Survey (ESS). In general, culture is a collective identity based on certain norms, values and beliefs. This informal yet widely accepted definition supports the use of attitudinal surveys, because it is the most straightforward manifestation of people's perception of norms, values and beliefs. This conforms with the ESS database, where one of the aims is "to monitor and interpret changing public attitudes and values within Europe". Furthermore, using attitudinal responses has a solid theoretical foundation. Individual attitudes are to a large extent shaped by intrinsic cultural characteristics. Notably, Hofstede et al. (2010) have argued that similar attitudes and beliefs are driven by the collective "mental programming" of people with a similar cultural background. ${ }^{7}$

Immigrants' self-identities are taken to be two-dimensional: the perception of the cultural value of one's country of origin and the dichotomous perception of being an immigrant or not. We use two distance measures to make this distinction in self-identity. Firstly, "Bilateral Cultural Distance" (hereafter denoted as $B C D$ ), which is constructed to measure the cultural distance between a migrant's own ethnic group $i$ and the native group in the receiving region $j$, written as:

$$
B C D_{i j}=\mid \text { Attitudes }_{i}-\text { Attitudes }_{j} \mid
$$

\footnotetext{
${ }^{6}$ The measurement of cultural diversity captures more than merely the fractionalization index. See Montalvo and Reynal-querol (2005) or Ager and Brückner (2013) for a discussion of polarization; and Nijkamp and Poot (2013) for an overview of cultural diversity measures, where they consider, in turn, abundance, dispersion and socio-cultural distance-related measures of diversity.

${ }^{7}$ Examples of using indicators of individual values and beliefs to measure culture can be found in Belot and Ederveen (2012); Grief (1994); Tabellini (2010); Tadesse and White (2009).
} 
where $B C D_{i j}$ is a between-group measure, involving both origin $i$ and destination $j$. Secondly, "Average Cultural Distance" (hereafter denoted as $A C D$ ), which is constructed as a weighted average value of all the cultural distances between every immigrant $m$ and the native culture in the receiving region $j$ (weights denoted as $p_{m}$ ), written as:

$$
A C D_{j}=\sum_{m \text { living in } j} p_{m} \cdot \mid \text { Attitudes }_{m}-\text { Attitudes }_{j} \mid
$$

where $A C D_{j}$ is a region-specific measure (similar to cultural diversity), describing the overall cultural proximity level between the natives and the residing immigrants as a whole.

More details about the ESS data set and how we use attitudinal responses to construct cultural distance variables will be discussed further in Section 4 .

\section{Empirical Model}

The equilibrium sorting model proposed by Bayer et al. (2004a) is the starting point for our methodological framework. We use it to examine migrants' heterogeneous preferences and the contribution of cultural composition to regional attractiveness. ${ }^{8}$

\subsection{The equilibrium sorting model}

We model a population of migrants, indexed by $m=1, \ldots, M$. Their countries of birth are indexed by $i=1, \ldots, I$ and they have to choose a destination from all possible alternatives, indexed by $j=1, \ldots, J$. Each migrant maximizes her indirect utility

\footnotetext{
${ }^{8}$ This differentiated "product" approach is typically referred to as the Berry-Levinsohn-Pakes (BLP) approach (Berry et al., 1995), and has recently been applied to a number of empirical studies (Klaiber and Phaneuf, 2010; Murdock, 2006; van Duijn and Rouwendal, 2012).
} 
function in choosing destinations:

$$
\max _{j} V_{m i j, t}=\alpha_{m} \mathbf{Z}_{\mathbf{j}, \mathbf{t}-\mathbf{1}}+\gamma \mathbf{P}_{\mathbf{i j ,}, \mathbf{t}-\mathbf{1}}+\eta_{j, t}+\varepsilon_{m i j, t} .
$$

The indirect utility migrant $m$ from country $i$ derives from living in region $j$ at time $t$ depends firstly on a number of regional characteristics and amenities $\mathbf{Z}_{\mathbf{j}, \mathbf{t}-\mathbf{1}}$ (such as GDP, unemployment ratio, cultural diversity $D i v_{j}$, average cultural distance $A C D_{j}$, etc.) observed at time $t-1$, and secondly, on certain pair-specific information $\mathbf{P}_{\mathbf{i j}, \mathbf{t}-\mathbf{1}}$ (such as bilateral cultural distance $B C D_{i j}$ ) at time $t-1$. For simplicity, we omit the time subscript $t$ in the subsequent text.

The valuation parameter $\alpha_{m}$ is then written as a function of the migrants' individual characteristics $\mathbf{X}_{\mathbf{m}}$, including age, gender, education, occupation, etcetera, written as:

$$
\alpha_{m}=\beta_{0}+\beta\left(\mathbf{X}_{\mathbf{m}}-\overline{\mathbf{X}}\right)
$$

The error structure in the indirect utility function is composed of both regional characteristics $\eta_{j}$, which we do not observe ${ }^{9}$, and individual-specific errors $\varepsilon_{m i j}$.

We rewrite our indirect utility function by substituting equation (5) into equation (4):

$$
V_{m i j}=\lambda_{j}+\left(\mathbf{X}_{\mathbf{m}}-\overline{\mathbf{X}}\right) \beta \mathbf{Z}_{\mathbf{j}}+\gamma \mathbf{P}_{\mathbf{i j}}+\varepsilon_{m i j},
$$

with

$$
\lambda_{j}=\beta_{0} \mathbf{Z}_{\mathbf{j}}+\eta_{j}
$$

We estimate the model in two stages. Assuming that the $\varepsilon_{m i j}$ 's are distributed as a Type

\footnotetext{
${ }^{9}$ These regional unobserved characteristics (which are observed by the migrants) might include social tensions, cultural or natural amenities, and specific (regional) institutional settings.
} 
I Extreme Value distribution, equation (6) is estimated accordingly as a multinomial logit model with alternative-specific constants in the first stage. These constants (the $\lambda_{j}$ 's as specified in equation (7)) measure a region's attractiveness. The coefficients $\beta$ measure the interaction parameters which describe heterogeneous preferences for different regional characteristics and amenities, while the coefficients $\gamma$ measure the impact of pair-specific variables $\mathbf{P}_{\mathbf{i j}}$.

In a nutshell, the first stage aims to tease out the heterogeneous preferences of migrants in choosing destinations, while the subsequent second stage is of more interest to us, because it aims to explain the contribution of cultural composition to regional attractiveness. In the second stage, the estimated $\lambda_{j}$ 's are further regressed on $\mathbf{Z}_{\mathbf{j}}$. We have to deal with endogeneity problems in this step, since the unobserved regional characteristics $\left(\eta_{j}\right)$ are very likely to be correlated with both the regressors $\left(\mathbf{Z}_{\mathbf{j}}\right)$ and regional attractiveness $\left(\lambda_{j}\right)$.

\subsection{Endogeneity and artificial instrumental variables}

As previously mentioned, unobserved heterogeneity may cause an estimation bias. Therefore, we resort to instrumental variable (IV) estimation. The compositional amenity we are most interested in is the $A C D$ index. If, for whatever reason (but not for the $A C D$ index nor for other observed variables), many immigrants with similar cultural characteristics choose region $j$, then our coefficient for the $A C D$ index is biased upwards. The unobserved characteristics $\eta_{j}$ 's then lead to an overestimate of the coefficient $\beta_{A C D}$. Similarly, if unobserved regional characteristics cause migrants with different cultural characteristics to choose region $j$, our coefficient for the $A C D$ index is biased downwards. To solve for this, we instrument the $A C D$ index by using an artificial instrument-where we argue that our instrument is correlated with the region's cultural composition but not directly with its present attractiveness to potential migrants. 
The instrument we use is an artificial constructed vector $A C D^{*}$ solved from the multinomial logit model while forcing the unobserved heterogeneity $\eta$ to be zero. This method was used previously in Bayer et al. (2004a) to deal with the correlation between price and unobserved housing and neighbourhood quality. ${ }^{10}$ In our work, an instrument is constructed by solving for the vector of ACD that will clear the market ${ }^{11}$, if there were no unobserved heterogeneity.

To do so, we first define $\pi_{m j}$ to be the probability that migrant $m$ chooses region $j$. If the freedom of movement assumption is not violated, then the following equalities have to hold:

$$
P O P_{j}=\sum_{m=1}^{M} \pi_{m j}
$$

where $P O P_{j}$ denotes the total population of immigrants living in region $j$ observed in our sample. We now impose that $\eta_{j}$ is zero and define a new variable $A C D^{*}$ as the instrument for ACD. Now, rewrite equation (8) as:

$$
P O P_{j}=\sum_{m} \frac{\exp \left(w_{j}^{m}\left(A C D^{*}\right)\right)}{\sum_{j=1}^{J} \exp \left(w_{j}^{m}\left(A C D^{*}\right)\right)}, \text { for } m \text { in } j
$$

where $w_{j}^{m}$ is the deterministic part of equation (6), with the variable for $A C D$ replaced by $A C D^{*}$. If $A C D^{*}$ is the solution for which the equalities (9) hold, we have then found an instrumental variable that is, by definition, uncorrelated with $\eta_{j}$, and should in theory be related to the $A C D$ index. This approach requires an iterative procedure for both steps. Initial values of $\beta_{k 0}$ are obtained by estimating equation (7) using OLS, while the initial value of $\lambda_{j}$ is the predicted value according to OLS coefficients. The estimates of $\beta_{k 0}, \lambda_{j}$, together with all $\beta$ coefficients from equation (6), are then used to calculate a

\footnotetext{
${ }^{10}$ See also Bayer et al. (2004b) for an application to school quality, and van Duijn and Rouwendal (2012) for an application to cultural heritage.

${ }^{11}$ We consider living in a region is a product to be purchased by migrants, and each migrant only purchases one unit product with a particular package of regional characteristics and amenities. The local authorities provide the products in the market by making production decisions on what packages of characteristics and amenities are to be assembled (Rosen, 1974).
} 
new $A C D^{*}$ in the equalities in equation (9), after imposing $\eta_{j}=0$ for all $j$. The new vector we have solved is then used as an instrumental variable for the $A C D$ index in equation (7). The $\beta_{0}$ coefficients are then updated as 2SLS coefficients. The new values of $\beta_{0}$ 's and $\lambda_{j}$ are again inserted into equation (9) in the same way as before. This process is repeated, until the procedure leads to convergence which yields the artificial instrument $A C D^{*}$.

To summarize, the artificial instrumental variable created can be regarded as the exogenous component of the $A C D$ index (it is by definition independent of unobserved heterogeneity). Moreover, it should be correlated with the observed value of $A C D$. Consequently, it is a plausible instrument to be used in an instrumental variable estimation. Although cultural diversity is of less interest to us, we use the same iterative procedure to find an instrument for the Div index. Hence, we have (theoretically) valid instruments for both the $A C D$ and the Div variable, which are otherwise most likely to be endogenous in the second-stage estimation.

\section{Data and Variables}

A full estimation of the model requires three types of data: the individual sociodemographic characteristics $\mathbf{X}_{\mathbf{m}}$; the regional characteristics and amenities $\mathbf{Z}_{\mathbf{j}}$; and origin-destination specific information $\mathbf{P}_{\mathbf{i j}}$. The European Social Survey (ESS) Multilevel Data is a rich data set that is consistent with our research goals. It is a merged database that links individuals to their corresponding contextual information, both regionally and nationally. Up until now, Round 4 in year 2008 and Round 5 in year 2010 are available as cross-sectional data, which contain respectively, 56,752 and 50,781 respondents. In addition, the geodesic distances between countries are provided by VU Geoplaza, and regional characteristics of sectoral composition are supplemented by the Cambridge 
Econometrics database. ${ }^{12}$

\subsection{The sample and the descriptive statistics}

An individual is identified as a first-generation immigrant if both she and her parents were born outside the country of residence. The analysis is carried out on a sample of first-generation immigrants from the ESS Round 5, who were at least 18 years old at the time of immigration. ${ }^{13}$ We are then left with a sample of 1,935 , who were most likely to make the immigration decision on the basis of regional or urban attractiveness (other than family ties). The living areas of the sample cover 61 regions at the NUTS1 ${ }^{14}$ level in 20 countries in Europe: Belgium, Bulgaria, Switzerland, Cyprus, Czech Republic, Germany, Denmark, Spain, Finland, France, Greece, Hungary, Ireland, the Netherlands, Norway, Poland, Portugal, Sweden, Slovenia and Slovakia.

The individual socio-demographic characteristics $\mathbf{X}_{\mathbf{m}}$ include gender, education, marital status, age when immigrated, occupation, income and household composition. Table 1 shows that immigrants mainly work in the manufacturing and service sectors. Moreover, on average immigrants earn less than natives.

\section{[INSERT TABLE 1 HERE]}

The regional characteristics $\mathbf{Z}_{\mathbf{j}}$ come from the ESS Round 4 in year 2008 and the Cambidge Eonometrics database. Our analysis includes: population density; gross enrollment ratio; unemployment ratio; life expectancy; period growth rates of agriculture; manufacturing and service sectors; institutional quality; and a capital dummy for each NUTS1 region.

\footnotetext{
${ }^{12}$ More details can be found in http://geoplaza.ubvu.vu.nl and http://www. camecon.com/.

${ }^{13}$ Individuals who were younger than 18 are unlikely to have made an independent migration decision.

${ }^{14}$ The Nomenclature of Territorial Units for Statistics, NUTS, is a geocode standard for referencing the administrative divisions of countries for statistical purposes, developed by the European Union.
} 
Cultural diversity, as one of the compositional amenities, is measured by the index of fractionalization, as mentioned in Section 2. The other compositional amenity, $A C D$, will be further elaborated in the next subsection.

As pair-specific information $\mathbf{P}_{\mathbf{i j}}$, we include three variables in our analysis. To measure the network effect, the first variable is the diaspora from country $i$ living in region $j$, where we use the ESS Round 4 data to calculate the share of different ethnic groups in a specific region. The second variable is the geodesic distance between country $i$ and region $j$, where we use the data from VU Geoplaza to calculate the distance matrix. We add it to measure how geographical proximity affects migrants' choice. The third variable is the bilateral cultural distance (BCD) between country $i$ and region $j$, which will be further elaborated in the next subsection as well.

Finally, to make all coefficients comparable, we standardize all variables.

\subsection{The construction of cultural distance variables}

In Section 2, we briefly discussed the validity of using attitudinal responses to quantify cultural distance. The ESS Round 4 collects attitudinal responses from surveys on the basic values and beliefs of individuals, and these questions cover a wide range of issues. In our analysis, we chose 116 questions covering individual attitudes towards (1) the media and social trust; (2) politics; (3) subjective well-being, social exclusion, religion, national and ethnic identity; and (4) human values. ${ }^{15}$ Most of the questions are phrased as a plain statement. In most cases, the respondents were asked to indicate the extent of agreement on a scale of 0-10. One illustrative example is presented below:

"Using this card, please tell me on a score of 0-10 how much you personally trust each of the institutions I read out. 0 means you do not trust an institution

\footnotetext{
${ }^{15} \mathrm{~A}$ selection of survey questions and the average responses can be found in Table 7 in the Appendix.
} 
at all, and 10 means you have complete trust."

A principal component analysis (PCA) was conducted to summarize all these attitudinal responses. ${ }^{16} \mathrm{PCA}$ reduces these responses into fewer principal components $\left(F_{1}, \ldots, F_{Q}\right)$ for each individual, where $Q$ is the number of components. $Q$ is chosen to be the number of factors with eigenvalues over 1 , and is set to be 29 in our subsequent analysis for 116 attitudinal responses. These components explain around $60 \%$ of the variation of the responses. PCA is able to reduce multiple dimensions to a great extent, while it also circumnavigates multicollinearity of the responses.

We use the inverse of the inclusion probabilities as weights $p . F^{m}$ and $F^{n}$ are both $Q \times 1$ vectors, denoting cultural principal components for the migrant indexed by $m$, and for the native indexed by $n$. A representative native in region $j$ has a principal component $F^{j}$, which is equal to the weighted average of $F^{n}$ in region $j\left(F^{j}=\sum_{n \in j} p_{n} \cdot F^{n}\right)$, while a representative migrant originally from country $i$ has a principal component $F^{i}$, which is equal to the weighted average of $F^{m}$ from country $i\left(F^{i}=\sum_{m \in i} p_{m} \cdot F^{m}\right)$.

The bilateral cultural distance $B C D_{i j}$ between the mainstream culture of origin $i$ and that of region $j$ is then measured by group distances: ${ }^{17}$

$$
B C D_{i j}=\left|F^{i}-F^{j}\right|
$$

The average cultural distance $A C D_{j}$ for region $j$ needs to take into account every individual-specific cultural distance existing in the region. Therefore $A C D$ is defined as a weighted average of cultural distance between $F^{j}$ and every immigrant $F^{m}$ living in

\footnotetext{
${ }^{16}$ See Tubadji and Nijkamp (2014) for an example of PCA in cultural impact analysis.

${ }^{17}$ We use Euclidean distance, e.g.

$$
\left|F^{a}-F^{b}\right|=\sqrt{\left(F_{1}^{a}-F_{1}^{b}\right)^{2}+\cdots+\left(F_{Q}^{a}-F_{Q}^{b}\right)^{2}} .
$$

An alternative definition of bilateral cultural distance $B C D_{m j}$ between migrant's individual attitudes and region $j$ 's mainstream culture has also been tried out, and the results do not differ from $B C D_{i j}$.
} 
region $j$, written as:

$$
A C D_{j}=\sum_{m \text { living in } j} p_{m} \cdot\left|F^{m}-F^{j}\right| .
$$

Figure 1 shows the map of cultural diversity and average cultural distance at the NUTS1 level. The patterns of the two cultural composition indicators are quite different. There is a sharp contrast between the regions in terms of cultural diversity, while the changes are much more moderate in terms of $A C D$. Generally speaking, Western Europe is much more culturally diversified than Eastern Europe. Ireland and the Nordic countries are also highly culturally diversified. This fits our common impression that popular migration destinations are always marked by high cultural diversity. Regions in the Nordic countries, Switzerland, Ireland, and Madrid score relatively low in terms of $A C D$, indicating a more similar cultural composition, while regions in France, Germany, Greece, and Romania are characterized by a relatively high $A C D$.

\section{[INSERT FIGURE 1 HERE]}

It is noteworthy that a fractionalized composition does not necessarily imply a high degree of $A C D$ as we might initially think. Some regions in Eastern Europe (Romania, Poland and Bulgaria) have a low degree of cultural diversity, but the cultural distances between the natives and the immigrants are substantial. Belgium and Switzerland, however, remain low in $A C D$, even though they are the most culturally diversified regions in Europe.

\section{Estimation Results}

This section presents and discusses the results of the sorting model estimation for the European regions using the above-mentioned ESS data set. The estimation is implemented 
in two stages, where the results in the first stage refer to the migrants' heterogeneous preferences, while the results in the second stage explain how societal cultural composition contributes to regional or urban attractiveness.

\subsection{First stage}

The first stage of the estimation procedure yields 132 coefficients on terms that interact with individual characteristics across different regional characteristics ${ }^{18}$, and also 3 coefficients for the three pair-specific variables $\left(\mathbf{P}_{\mathbf{i j}}\right)$. This permits greater flexibility in modelling the heterogeneous preferences of migrants. The first stage also addresses regional attractiveness (the region specific $\lambda$ ) across alternatives and prepares for the second stage of the estimation.

In the first stage, the heterogeneous preferences for compositional amenities is of particular interest to us. Table 2 reports some significant cross effects of immigrants and compositional amenities. Younger migrants and those without children have a preference for regions with high cultural diversity compared with their counterparts. The higher the regional ACD is, the less attractive it is to older migrants, agricultural workers, females, and EU migrants.

\section{[INSERT TABLE 2 HERE]}

There are three estimates, $\gamma$, for the pair-specific variables. The ethnic-specific network has a positive effect in attracting migrants of its own ethnicity. Secondly, the smaller the $\mathrm{BCD}$ is between a migrant's host culture and the region's mainstream culture, the more likely she will be moving there. Thirdly, being close to a region greatly increases

\footnotetext{
${ }^{18}$ There are 12 variables for individual characteristics $\mathbf{X}_{\mathbf{m}}$, and 11 variables for regional characteristics and amenities $\mathbf{Z}_{\mathbf{j}}$, respectively. The full estimation results for all variables are available on request.
} 
the probability of moving there. It is noteworthy that cultural proximity is valued about three times higher than geographical proximity by migrants.

Figure 2 shows the relative attractiveness of the NUTS1 regions, based on the alternativespecific constants $\lambda_{j}$. Again, the colours of the Western European areas are darker than those of the Eastern European areas. Ireland and the Nordic countries turn out to have a high regional attractiveness. To determine the relationship between cultural compositional amenities and regional attractiveness is not as simple as merely comparing Figure 1 and Figure 2. Therefore, we need to proceed to the second stage, and explore the relative contribution of different characteristics and amenities to regional attractiveness $\lambda_{j}$

\section{[INSERT FIGURE 2 HERE]}

\subsection{Second stage}

The second stage of the estimation procedure is presented in Table 3. The dependent variable is obtained from the first stage as alternative-specific constants $(\lambda)$, which imply regional attractiveness. The regressors are regional characteristics and amenities: population density; gross enrollment ratio; unemployment; life expectancy; institutional quality; capital, annual growth of each sector; cultural diversity; and average cultural distance. The OLS results in columns(1) and (2) show the positive impact of cultural diversity and the negative impact of average cultural distance. The order of magnitude becomes slightly lower when we control for country fixed effects, but the estimates still remain significant. In the following specifications, we deal with unobserved heterogeneity as discussed in Section 3.2 and use our artificial instrumental variables. In columns (3) and (4), the artificial instrumental variable alone performs well, as shown in the diagnostic statistics. The F-test statistics in the auxiliary regression are 8.20, implying 
a high level of relevance. The instrument, which is the equilibrium $A C D$ value, is, by definition, orthogonal to unobserved heterogeneity but relevant to the observed $A C D$ in reality. Interestingly, the negative impact of average cultural distance becomes stronger in both specifications compared with the OLS estimates. Columns (5) and (6), where both Div and $A C D$ are instrumented, seem to be qualitatively similar to columns (3) and (4).

\section{[INSERT TABLE 3 HERE]}

In all specifications, the two indicators of cultural composition are considered as endogenous variables to be instrumented. Ottaviano and Peri (2005b) and some subsequent studies have used historical population share information and geography (distance to gateway cities, etc.) as instruments. ${ }^{19}$ Our artificial instrument variables for cultural composition work at least as good as the instruments used in previous research. Other regional variables are also possibly endogenous, but only in the long run. Most of the economic indicators are held invariant over a short period of time, and we therefore take these as exogenous controls.

In general, the order of magnitude of the $A C D$ index increases in the IV estimation compared with the OLS estimation. Migrants appear to sort into the same region due to unobserved heterogeneity, and $A C D$ matters even more for regional attractiveness when we have controlled for sorting. Given a certain level of cultural diversity, a relatively homogeneous cultural composition is a powerful attractor for future migrants. The policy implication is clear. "Civic integration" and "multiculturalism" are not necessarily at odds with each other. Both of them are beneficial for regions to increase their attractiveness. Clearly, this finding suggests that an immigration department might seek to enhance

\footnotetext{
${ }^{19}$ We also tried traditional instrumental variables in the analysis, e.g. geographical features of regions as in Monfort (2009). The instruments were less strongly correlated with the two indicators of cultural composition with less significant but qualitatively similar results. The estimation results are available on request.
} 
the immigrants' learning of the official language and their acknowledgment of the host country society's basic norms and values. On the other hand, promoting educational penetration among immigrants could be a policy instrument to promote the immigrants' social assimilation. Cameron et al. (2012) do indeed show that the more education received, the more the immigrants behave like the natives.

Our results are consistent with the findings by Card et al. (2012), who find that compositional concerns are more important than economic concerns. Immigration reshapes the composition of local population to a great extent, and this has gradually raised up an issue noticed by both natives and immigrants. Cultural diversity is indeed conducive to migration, yet may be accompanied by more social problems if the native group and the immigrant group are too dissimilar in culture. Saiz and Wachter (2011) also made the point that citizens' concerns seem to be strongly oriented towards localized social interactions. The higher the level of the $A C D$ index, the more likely is the occurrence of unrest and social tension.

\subsection{Language}

So far, we have not considered any language-related information. But language is a substantial factor in the choice of migration destination (Fafchamps and Shilpi, 2013), especially in the multilingual European context—both within countries and within some regions. We chose a subsample of EU migrants ${ }^{20}$, and created a dummy for being able to speak the native language in the receiving area.

The regressions for the EU sample also test the validity of the freedom of movement assumption, because they face largely similar immigration policies and political envi-

\footnotetext{
${ }^{20} \mathrm{An}$ estimation of a discrete choice model requires variation within each individual's choice set. The language dummy is quite unlikely to vary for non-EU migrants. Therefore, we drop non-EU migrants for this extension.
} 
ronments. In the choice of migration destination, the potential set of regions available to migrants differs due to legal barriers for migration and migration costs (e.g. visa application). This ensures the homogeneity of the choice set to some extent. 55 NUTS1 regions are analysed in this specification.

\section{[INSERT TABLE 4 HERE]}

In the first stage, the estimates for the heterogeneous preferences $\beta$ 's do not change much, but the estimates for the $\gamma$ 's do change. Table 4 shows language as a positive pulling factor to attract migrants. Even when controlling for language, BCD is still a concern for EU migrants. The estimates for network effects and geodesic distance are no longer significant. In the second stage, the estimates for the $\beta_{0}$ 's are consistent with those for the whole sample, with higher orders of magnitudes. EU migrants seem to be especially concerned about regional composition amenities, and the $A C D$ turns out to be a crucial factor in contributing to regional attractiveness.

\subsection{Spatial extension}

Finally, we extend our model by considering the possible presence of spatial autocorrelation: namely, that the impact of the cultural environment can possibly extend over geographical boundaries. Thus, a region could generally be regarded as more attractive when being close to another attractive region and migrants might therefore choose to live close to a region which has their desired societal cultural composition. To take into account the possibility that the attractiveness of a specific region may be partially affected by its surrounding regions, the baseline model is extended by including the neighbouring regions' attractiveness $\lambda$, weighted by a contiguity matrix $\mathbf{W}$. We now 
utilize a spatial autoregressive model (SAR: Anselin, 1988),

$$
\lambda=\rho \mathbf{W} \lambda+\beta \mathbf{Z}+u
$$

In our spatial econometric specifications, 57 regions at the NUTS1 level from 19 countries are considered. As can be seen in equation 5, the estimates for Div and $A C D$ still remain significant at the 0.05 level, consistent with our main findings in Table 3. In columns (1) and (2), the socio-cultural composition can exert a sufficient impact on neighboring regions. When allowing for both country fixed and regional dependence in column (3) in Table 5, our results still hold. However, both Div and $A C D$ have smaller values compared with those in column (6) in Table 3. Thus, the impact of the socio-cultural composition is clearly diluted by allowing for the neighbouring regions' attractiveness.

[INSERT TABLE 5 HERE]

In column (3), $\rho$ becomes insignificant in the fixed effect specification, indicating that the impact of the socio-cultural composition is more affected by spatial heterogeneity than by spatial auto-correlation. Regional attractiveness hinges heavily upon countries' institutional settings.

\section{Robustness Checks}

In this section, some further checks are made to validate our main findings. Three issues are of particular interest to us. Firstly, does the date of collecting respondents' attitudinal responses matter for the result? Secondly, how valid is the constructed $A C D$ index in our analysis and is the result subject to the selection of the cultural variables? Thirdly, how can we adjust for between-group cultural distances among immigrants? 
Since a cross-sectional data set is used for the empirical analysis, these attitudinal answers in the ESS Round 4 were not collected at the time of the migration decision. ${ }^{21}$ If migrants' values and beliefs converge to the regional mainstream culture over the years, the true $A C D$ index should be much larger due to assimilation. This is an important problem, because around $60 \%$ of the migrants in our sample immigrated over 10 years ago. To minimize the assimilation effect to the least possible extent while still preserving sufficient individuals in the sample, we selected a subsample of migrants who have just immigrated in the most recent decade (years 2000-2010).

The estimation is implemented on a subsample of 825 recent migrants in 55 NUTS1 regions. In the first stage, the network effect turns out to be insignificant, but cultural proximity and geographical proximity still matter. It is quite intuitive that earlier migrants (from, say, the 1990s or earlier) rely heavily on the ethnic network, while recent migrants rely relatively less on ethnic networks. We employ the specification in which we control for country fixed effects, and use the two artificial instruments in the second stage. The estimates for both Div and ACD keep the same signs, and the estimate for Div increases. Seemingly, cultural diversity is attractive to recent migrants, while average cultural distance is still taken into account by them. In addition, the $\beta$ estimates for migrants in the most recent decade do not differ significantly from the estimates for the whole sample, and this validates the stable preference pattern assumption.

We now proceed to the second issue. A subset of attitudinal responses is chosen to validate the constructed $A C D$ index. The advantage of the ESS is the richness of its information that provides a quantitative description of cultural distances between individuals. In the main regression, we used all attitudes related to culture. In doing so, we focus more on cultural differences among individuals, yet less on mapping the attitudes to certain

\footnotetext{
${ }^{21}$ This issue also applies to other regional characteristics. Since more of them remain relatively invariant over time (e.g. sectoral growth), we focus only on the $A C D$ variable which is most likely to bias the results.
} 
cultural qualities. However, in previous cultural-related literature (Grief, 1994; Tabellini, 2010; Tadesse and White, 2009), researchers are more specific in choosing cultural-specific questions that embody certain cultural qualities.

Trust, control, respect, and obedience are four features that have been directly used before to proxy culture. We chose the related questions from the ESS that reveal attitudes to these features. As is shown in Table 6, natives and immigrants differ greatly in terms of the four features except with respect to obedience. The new $A C D$ index still has significant variation. We repeat our previous regressions. The IV estimates for Div and $A C D$ keep the same signs as the main findings, but both have a lower order of magnitude, respectively 0.40 and -0.33 . The change should be attributed to a smaller variation of the new $A C D$ index, since fewer attitudinal questions were selected. The cultural difference is weakened in this scenario, so it has a much more moderate effect on regional attractiveness.

\section{[INSERT TABLE 6 HERE]}

Finally, we replace the $A C D$ index with the mean variation of attitudes principal components in a specific region. Instead of focusing on the distinction of the native group and the immigrant group, this crude measure takes into account every individual's attitudes (including those of the natives) regardless of the country of origin. This measure quantifies the degree of heterogeneity within a society and yields similar results as column (5) and (6) in Table 3.

In summary, our main results are robust, when we take into account the possible assimilation of migrants, the selection of attitudinal responses, and an alternative way to describe cultural composition. The stable preference pattern assumption seem to be valid in our case. The timing issue of responses collected does not weaken our main finding. Using attitudinal responses in the ESS Round 4 in year 2008, we might underestimate the 
true $A C D$ index at the time of their immigration. When we carry out the analysis with the subsample of migrants in the most recent decade, the conclusion remains relatively robust. Secondly, in accordance with the previous literature, we try to map cultural qualities to these attitudinal responses. Though the new constructed $A C D$ index has lower variation, it still leads to significant results with more moderate estimates. Finally, to correct for between-group distances among immigrants, we tried a crude measure that takes into account every individual's attitudinal responses. The results are consistent with the main analysis.

\section{Concluding Remarks}

Our research has investigated whether migrants are attracted by a region's socio-cultural composition. We focused primarily on the impact of cultural distance. Theoretically, its impact is ambiguous at first sight. On the one hand, a large cultural distance enriches societal norms, values and beliefs, and people might perceive large average cultural distance as a positive amenity. On the other hand, these wide cultural gaps between natives and immigrants may breed miscommunication, misunderstandings, and social conflict.

By studying a sample of 1,935 first-generation immigrants above 18 years old from the European Social Survey Round 5, we first looked at how individuals made their migration destination choice on the basis of regional characteristics and societal cultural compositions. In general, migrants prefer to move to regions with a cultural background similar to themselves, and this holds especially for EU migrants. Younger migrants have a higher tolerance for regional average cultural distance than older migrants. We also find that migrants are more likely to choose regions geographically close to their country of origin. The network effect is an important factor for the earlier generation of migrants, 
and non-EU migrants are influenced by it much more than EU migrants. Although the analysis is limited to the sample of migrants who have already made the move, it has implications for future migrants' destination choices, who have similar preference patterns.

In the second stage, we compared the attractiveness of 61 regions at the NUTS1 level in 20 European countries, and identified the contribution of cultural diversity and average cultural distance to regional or urban attractiveness. We found a significant and robust negative correlation between average cultural distance and attractiveness, while cultural diversity has a positive impact, as confirmed by previous studies. These impacts can extend outside the local area and increase (or decrease) neighbouring regions' attractiveness. These results are robust to the period of migration, whether migrants originate from the EU and to variations in the construction of average cultural distance.

From a policy perspective, given the premise that local authorities would like to attract more migrants, it seems to be plausible to enhance cultural integration and assimilation as a marginal attraction force. We note that this is not necessarily opposed to increasing cultural diversity, because diversity only refers to the proportion of people from different ethnicities. The thrust of integration is to narrow the cultural distance between immigrants and the host society, and to make immigrants understand a country's social norms, principles, and institutions. ${ }^{22}$ Not only do the immigrants who already reside within a region then derive higher utilities, but also do future incoming immigrants.

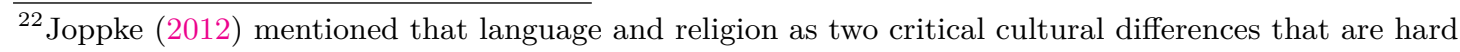
to be integrated.
} 


\section{References}

Ager, P. and M. Brückner (2013). "Cultural diversity and economic growth: evidence from the US during the age of mass migration". European Economic Review 64.November, pp. $76-97$.

Alesina, A. and E. La Ferrara (2005). "Ethnic diversity and economic performance". Journal of Economic Literature XLIII.September, pp. 762-800.

Anselin, L. (1988). Spatial Econometrics: Methods and Models. Kluwer Acaademic.

Bakens, J., P. Mulder, and P. Nijkamp (2013). "Economic impacts of cultural diversity in the Netherlands: productivity, utility, and sorting". Journal of Regional Science 53.1, pp. 8-36.

Bayer, P., R. Mcmillan, and K. Rueben (2004a). "An equilibrium model of sorting in an urban housing market". NBER. 10865th ser. No. 10865.

Bayer, P., F. Ferreira, and R. McMillan (2004b). "Tiebout sorting, social multipliers and the demand for school quality". NBER No. 10871.

Belot, M. and S. Ederveen (2012). "Cultural barriers in migration between OECD countries". Journal of Population Economics 25.3, pp. 1077-1105.

Berry, S., J. Levinsohn, and A. Pakes (1995). "Automobile prices in market equilibrium". Econometrica 63.4, pp. 841-890.

Borjas, G. J., S. G. Bronars, and S. J. Trejo (1992). "Self-selection and internal migration in the United States." Journal of Urban Economics 32.2, pp. 159-85.

Borjas, G. J. (1987). "Self-selection and the earnings of immigrants". American Economic Review 77.4, pp. 531-553.

Cameron, L., N. Erkal, L. Gangadharan, and M. Zhang (2012). "Cultural integration: experimental evidence of changes in immigrants' preferences". IZA Discussion Paper No. 6467.

Card, D., C. Dustmann, and I. Preston (2012). "Immigration, wages, and compositional amenities". Journal of the European Economic Association 10.1, pp. 78-119.

Carrington, W. J., E. Detragiache, and T. Vishwanath (1996). "Migration with endogenous moving costs". American Economic Review 86.4, pp. 909-930.

Caselli, F. and W. J. Coleman (2013). "On the theory of ethnic conflict". Journal of the European Economic Association 11.January, pp. 161-192.

Chen, Y. and S. S. Rosenthal (2008). "Local amenities and life-cycle migration: do people move for jobs or fun?" Journal of Urban Economics 64.3, pp. 519-537.

Chiswick, B. (1999). "Are immigrants favorably self-selected?" The American Economic Review 89.2, pp. 181-185. 
Fafchamps, M. and F. Shilpi (2013). "Determinants of the choice of migration destination". Oxford Bulletin of Economics and Statistics 75.3, pp. 388-409.

Florida, R. (2002). "Bohemia and economic geography". Journal of Economic Geography 2.1 , pp. 55-71.

Glaeser, E. L., J. Kolko, and a. Saiz (2001). "Consumer city". Journal of Economic Geography 1.1, pp. 27-50.

Grief, A. (1994). "Cultural beliefs and the organization of society : a historical and theoretical reflection on collectivist and individualist societies". Journal of Political Economy 102.5, pp. 912-950.

Haurin, D. R. (1980). "The regional distribution of population, migration, and climate". The Quarterly Journal of Economics 95.2, pp. 293-308.

Hofstede, G., G. J. Hofstede, and M. Minkov (2010). Cultures and Organizations: software of the mind.

Joppke, C. (2012). "The role of the State in cultural integration: trends, challenges and ways ahead". Washington, DC: Migration Policy Institute.

Klaiber, H. and D. J. Phaneuf (2010). "Valuing open space in a residential sorting model of the Twin Cities". Journal of Environmental Economics and Management 60.2, pp. $57-77$.

Mauro, P. (1995). "Corruption and growth". The Quarterly Journal of Economics 110.3, pp. $681-712$.

Monfort, P. (2009). "Territories with specific geographical features". Working Paper, European Union Regional Policy 02.

Montalvo, J. G. and M. Reynal-querol (2005). "Ethnic polarization, potential conflict, and civil wars". American Economic Review 95.3, pp. 796-816.

Murdock, J. (2006). "Handling unobserved site characteristics in random utility models of recreation demand". Journal of Environmental Economics and Management 51.1, pp. $1-25$.

Nijkamp, P. and T. Baycan (2012). "A socio-economic impact analysis of cultural diversity". Serie Research Memoranda, VU University Amsterdam, Faculty of Economics, Business Administration and Econometrics. 0012.

Nijkamp, P. and J. Poot (2013). "Cultural diversity: a matter of measurement". The Economics of Cultural Diversity. Edward Elgar, Cheltenham, forthcoming.

Ottaviano, G. I. and G. Peri (2005a). "The economic value of cultural diversity: evidence from US cities". Journal of Economic Geography 6.1, pp. 9-44.

Ottaviano, G. I. and G. Peri (2005b). "Cities and cultures". Journal of Urban Economics 58.2, pp. 304-337. 
Roback, J (1982). "Wages, rents, and the quality of life". The Journal of Political Economy 90.6, pp. $1257-1278$.

Rodríguez-Pose, A. and T. D. Ketterer (2012). "Do local amenities affect the appeal of regions in Europe for migrants?" Journal of Regional Science 52.4, pp. 535-561.

Rosen, S. (1974). "Hedonic prices and implicit markets : product differentiation in pure competition". The Journal of Political Economy 82.1, pp. 34-55.

Saiz, A. and S. Wachter (2011). "Immigration and the neighborhood". American Economic Journal: Economic Policy 3.May, pp. 169-188.

Scott, A. J. (2010). "Jobs or amenities? Destination choices of migrant engineers in the USA". Papers in Regional Science 89.1, pp. 43-63.

Tabellini, G. (2010). "Culture and institutions: economic development in the region of Europe". Journal of the European Economic Association 8.4, pp. 677-716.

Tadesse, B. and R. White (2009). "Cultural distance as a determinant of bilateral trade flows: do immigrants counter the effect of cultural differences?" Applied Economics Letters 17.2, pp. 147-152.

Tubadji, A. and P. Nijkamp (2014). "Altruism to strangers for our own sake: domestic effects from immigration". International Journal of Manpower, Special Issue: Culture and Labour 35.1/2, pp. 11-32.

van Duijn, M. and J. Rouwendal (2012). "Cultural heritage and the location choice of Dutch households in a residential sorting model". Journal of Economic Geography, pp. $1-28$. 
Figures

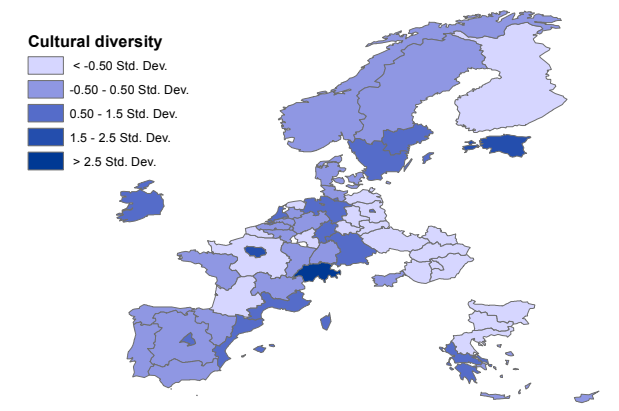

(a) Cultural diversity

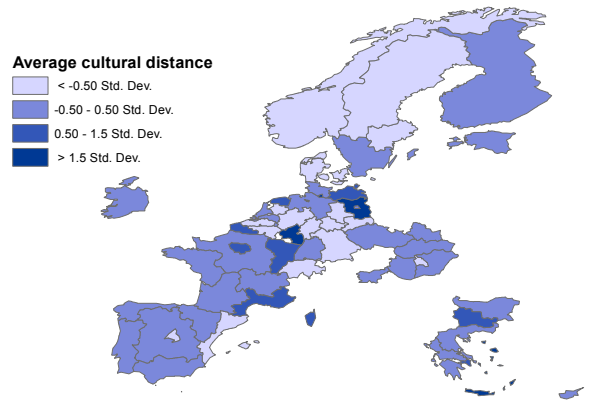

(b) Average cultural distance

Figure 1: CD and ACD of NUTS1 regions in Europe

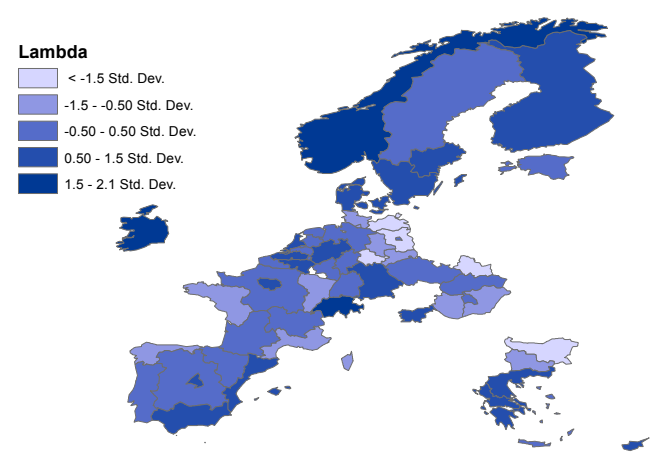

$\therefore$.

Figure 2: Relative attractiveness of NUTS1 regions, based on the alternative-specific constants $\lambda_{j}$ 


\section{Tables}

Table 1: Descriptive Statistics of Individual Characteristics

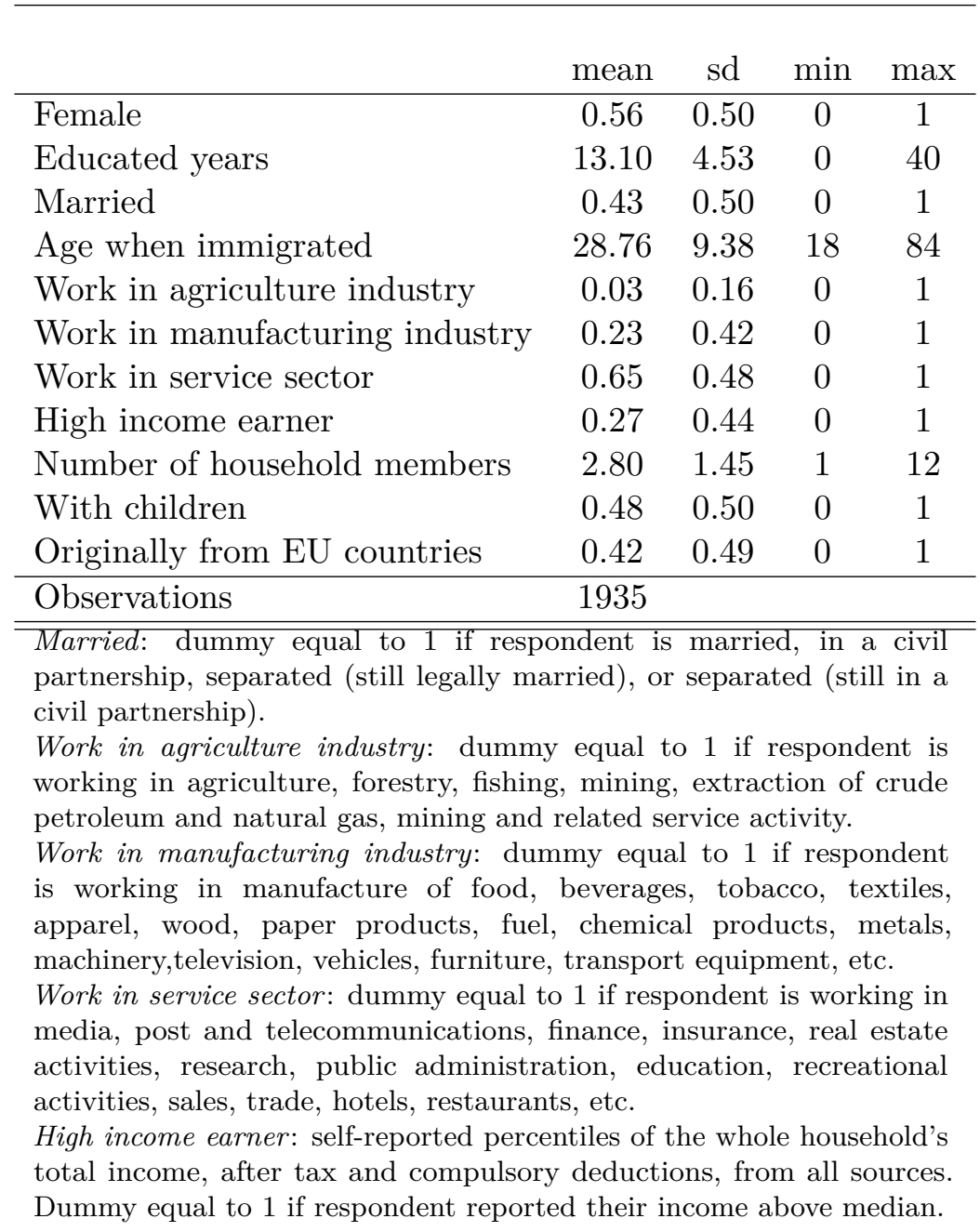


Table 2: First-Stage Estimation (selected results): $\beta$ for interaction terms, and $\gamma$ for pair-specific variables

\begin{tabular}{lcc}
\hline \hline$\beta$ & Cultural Diversity & Average Cultural Distance \\
\hline Age when immigrated & $-0.210^{* *}(0.021)$ & $-0.273^{* *}(0.041)$ \\
Agriculture worker & $-0.023(0.044)$ & $-0.120^{* *}(0.046)$ \\
Female & $-0.067(0.043)$ & $-0.146^{* *}(0.040)$ \\
With children & $-0.131^{+}(0.062)$ & $-0.034(0.196)$ \\
Originally from EU & $-0.086(0.069)$ & $-0.297^{*}(0.131)$ \\
\hline$\gamma$ & & \\
Network effect & $0.270^{* *}(0.071)$ & \\
Bilateral cultural distance & $-6.729^{* *}(1.146)$ & \\
Geodesic distance & $-1.819^{* *}(0.317)$ & \\
\hline Observations & 1935 & \\
Regions & 61 & \\
Log lik. & -5242.028 & \\
\hline \hline
\end{tabular}

Network effect/diaspora effect: the population share of one's own ethnic group in other regions. Standard errors in parentheses.

$+p<0.1,{ }^{*} p<0.05,{ }^{* *} p<0.01$. 
Table 3: Second Stage Estimation: $\beta_{0}$ for regional characteristics and amenities

\begin{tabular}{|c|c|c|c|c|c|c|}
\hline & $\begin{array}{c}(1) \\
\text { OLS }\end{array}$ & $\begin{array}{c}(2) \\
\text { OLS }\end{array}$ & $\begin{array}{l}\text { (3) } \\
\text { IV }\end{array}$ & $\begin{array}{l}\text { (4) } \\
\text { IV }\end{array}$ & $\begin{array}{l}\text { (5) } \\
\text { IV }\end{array}$ & $\begin{array}{l}\text { (6) } \\
\text { IV }\end{array}$ \\
\hline Population density & $\begin{array}{l}-0.189 \\
(0.140)\end{array}$ & $\begin{array}{l}-0.223 \\
(0.148)\end{array}$ & $\begin{array}{l}-0.032 \\
(0.325)\end{array}$ & $\begin{array}{c}-0.192^{+} \\
(0.106)\end{array}$ & $\begin{array}{l}-0.679 \\
(0.617)\end{array}$ & $\begin{array}{l}-0.585 \\
(0.357)\end{array}$ \\
\hline Gross enrollment ratio & $\begin{array}{l}0.260^{+} \\
(0.143)\end{array}$ & $\begin{array}{l}0.594^{* *} \\
(0.157)\end{array}$ & $\begin{array}{c}0.089 \\
(0.165)\end{array}$ & $\begin{array}{l}0.555^{* *} \\
(0.146)\end{array}$ & $\begin{array}{c}0.010 \\
(0.195)\end{array}$ & $\begin{array}{c}0.238 \\
(0.211)\end{array}$ \\
\hline Unemployment & $\begin{array}{c}-0.342^{*} \\
(0.137)\end{array}$ & $\begin{array}{c}-0.280^{+} \\
(0.161)\end{array}$ & $\begin{array}{l}-0.329 \\
(0.289)\end{array}$ & $\begin{array}{c}-0.299^{*} \\
(0.132)\end{array}$ & $\begin{array}{c}-0.171 \\
(0.238)\end{array}$ & $\begin{array}{c}-0.499^{*} \\
(0.214)\end{array}$ \\
\hline Life expectancy & $\begin{array}{c}0.075 \\
(0.326)\end{array}$ & $\begin{array}{l}-0.305 \\
(0.344)\end{array}$ & $\begin{array}{c}0.302 \\
(0.397)\end{array}$ & $\begin{array}{l}-0.303 \\
(0.247)\end{array}$ & $\begin{array}{c}0.024 \\
(0.428)\end{array}$ & $\begin{array}{c}-0.873^{*} \\
(0.396)\end{array}$ \\
\hline Growth of Agri. & $\begin{array}{c}0.195 \\
(0.210)\end{array}$ & $\begin{array}{l}0.352^{*} \\
(0.132)\end{array}$ & $\begin{array}{c}0.336 \\
(0.218)\end{array}$ & $\begin{array}{l}0.386^{* *} \\
(0.110)\end{array}$ & $\begin{array}{l}0.491^{+} \\
(0.259)\end{array}$ & $\begin{array}{l}0.600^{* *} \\
(0.215)\end{array}$ \\
\hline Growth of Manu. & $\begin{array}{l}0.179^{+} \\
(0.096)\end{array}$ & $\begin{array}{l}-0.247 \\
(0.170)\end{array}$ & $\begin{array}{c}0.140 \\
(0.143)\end{array}$ & $\begin{array}{c}-0.238^{+} \\
(0.130)\end{array}$ & $\begin{array}{l}-0.059 \\
(0.224)\end{array}$ & $\begin{array}{l}-0.432 \\
(0.265)\end{array}$ \\
\hline Growth of Ser. & $\begin{array}{c}0.097 \\
(0.178)\end{array}$ & $\begin{array}{c}0.125 \\
(0.146)\end{array}$ & $\begin{array}{c}-0.003 \\
(0.330)\end{array}$ & $\begin{array}{c}0.108 \\
(0.112)\end{array}$ & $\begin{array}{l}-0.196 \\
(0.366)\end{array}$ & $\begin{array}{c}-0.159 \\
(0.214)\end{array}$ \\
\hline Capital dummy & $\begin{array}{l}0.427^{* *} \\
(0.132)\end{array}$ & $\begin{array}{c}0.118 \\
(0.133)\end{array}$ & $\begin{array}{l}0.291^{+} \\
(0.166)\end{array}$ & $\begin{array}{c}0.112 \\
(0.097)\end{array}$ & $\begin{array}{c}0.086 \\
(0.167)\end{array}$ & $\begin{array}{c}0.190 \\
(0.172)\end{array}$ \\
\hline Institutional quality & $\begin{array}{c}0.365 \\
(0.295)\end{array}$ & $\begin{array}{c}0.200 \\
(0.272)\end{array}$ & $\begin{array}{c}0.088 \\
(0.451)\end{array}$ & $\begin{array}{c}0.245 \\
(0.178)\end{array}$ & $\begin{array}{l}-0.179 \\
(0.518)\end{array}$ & $\begin{array}{l}-0.120 \\
(0.497)\end{array}$ \\
\hline Cultural diversity & $\begin{array}{c}0.332^{*} \\
(0.121)\end{array}$ & $\begin{array}{l}0.236^{+} \\
(0.132)\end{array}$ & $\begin{array}{c}0.164 \\
(0.219)\end{array}$ & $\begin{array}{l}0.206^{*} \\
(0.099)\end{array}$ & $\begin{array}{l}1.401^{+} \\
(0.754)\end{array}$ & $\begin{array}{l}1.057^{*} \\
(0.495)\end{array}$ \\
\hline Average cultural distance & $\begin{array}{c}-0.429^{* *} \\
(0.094)\end{array}$ & $\begin{array}{c}-0.268^{* *} \\
(0.095)\end{array}$ & $\begin{array}{c}-1.539^{* *} \\
(0.492)\end{array}$ & $\begin{array}{c}-0.397^{*} \\
(0.171)\end{array}$ & $\begin{array}{c}-1.737^{* *} \\
(0.590)\end{array}$ & $\begin{array}{c}-0.725^{*} \\
(0.308)\end{array}$ \\
\hline Constant & $\begin{array}{c}-0.396^{*} \\
(0.168)\end{array}$ & $\begin{array}{l}0.622^{*} \\
(0.231)\end{array}$ & $\begin{array}{c}-0.396^{* *} \\
(0.123)\end{array}$ & & $\begin{array}{c}-0.396^{* *} \\
(0.140)\end{array}$ & \\
\hline Observations & 61 & 61 & 61 & 61 & 61 & 61 \\
\hline$R^{2}$ & 0.727 & 0.954 & 0.255 & 0.854 & -0.292 & 0.462 \\
\hline Country fixed effect & $\mathrm{N}$ & $\mathrm{Y}$ & $\mathrm{N}$ & $\mathrm{Y}$ & $\mathrm{N}$ & $\mathrm{Y}$ \\
\hline Div instrumented & - & - & $\mathrm{N}$ & $\mathrm{N}$ & Y & Y \\
\hline ACD instrumented & - & - & Y & $\mathrm{Y}$ & Y & Y \\
\hline \multicolumn{7}{|c|}{ F-test of excluded instruments } \\
\hline For $A C D$ & - & - & 8.20 & 3.57 & 5.25 & 1.70 \\
\hline For Div & - & - & - & - & 8.98 & 3.02 \\
\hline Underidentification test & - & - & Reject & Reject & Reject & Reject \\
\hline Weak identification test & - & - & Reject & Reject & Reject & Reject \\
\hline
\end{tabular}


Table 4: First-Stage Estimation for EU subsample

\begin{tabular}{lc}
\hline \hline$\gamma$ & \\
\hline Network effect & $0.270(0.177)$ \\
Bilateral cultural distance & $0.364^{+}(0.221)$ \\
Geodesic distance & $-0.065(0.240)$ \\
Language & $1.497^{* *}(0.103)$ \\
\hline Observations & 825 \\
Regions & 55 \\
\hline \hline Network effect/diaspora effect: the population share of one's own ethnic \\
group in other regions. \\
Language: dummy equals 1 if respondent can speak the language of the \\
receiving areas. \\
Standard errors in parentheses. \\
$+{ }^{*} p<0.1,{ }^{*} p<0.05,{ }^{* *} p<0.01$.
\end{tabular}


Table 5: Spatial Autoregressive Model

\begin{tabular}{|c|c|c|c|}
\hline & $\begin{array}{c}(1) \\
\lambda\end{array}$ & $\begin{array}{c}(2) \\
\lambda\end{array}$ & $\begin{array}{c}(3) \\
\lambda\end{array}$ \\
\hline Average cultural distance & $\begin{array}{c}-0.489^{* *} \\
(0.107)\end{array}$ & $\begin{array}{c}-0.614^{* *} \\
(0.112)\end{array}$ & $\begin{array}{c}-0.290^{* *} \\
(0.053)\end{array}$ \\
\hline Population density & $\begin{array}{r}-0.226^{+} \\
(0.124)\end{array}$ & $\begin{array}{l}-0.352^{*} \\
(0.144)\end{array}$ & $\begin{array}{c}-0.270^{* *} \\
(0.098)\end{array}$ \\
\hline Gross enrollment ratio & $\begin{array}{l}0.284^{* *} \\
(0.090)\end{array}$ & $\begin{array}{l}0.258^{* *} \\
(0.097)\end{array}$ & $\begin{array}{l}0.578^{* *} \\
(0.071)\end{array}$ \\
\hline Unemployment & $\begin{array}{l}-0.227^{*} \\
(0.107)\end{array}$ & $\begin{array}{r}-0.205^{+} \\
(0.116)\end{array}$ & $\begin{array}{c}-0.211^{+} \\
(0.109)\end{array}$ \\
\hline Life expectancy & $\begin{array}{l}-0.141 \\
(0.149)\end{array}$ & $\begin{array}{l}-0.199 \\
(0.163)\end{array}$ & $\begin{array}{l}-0.202 \\
(0.235)\end{array}$ \\
\hline Growth of Agr. & $\begin{array}{l}0.221^{*} \\
(0.094)\end{array}$ & $\begin{array}{l}0.266^{* *} \\
(0.102)\end{array}$ & $\begin{array}{l}0.366^{* *} \\
(0.083)\end{array}$ \\
\hline Growth of Manu. & $\begin{array}{l}-0.040 \\
(0.132)\end{array}$ & $\begin{array}{l}-0.062 \\
(0.142)\end{array}$ & $\begin{array}{l}-0.258^{*} \\
(0.104)\end{array}$ \\
\hline Growth of Ser. & $\begin{array}{l}0.250^{*} \\
(0.123)\end{array}$ & $\begin{array}{c}0.191 \\
(0.133)\end{array}$ & $\begin{array}{c}0.172 \\
(0.133)\end{array}$ \\
\hline Capital dummy & $\begin{array}{l}0.404^{* *} \\
(0.110)\end{array}$ & $\begin{array}{l}0.329^{* *} \\
(0.120)\end{array}$ & $\begin{array}{c}0.091 \\
(0.106)\end{array}$ \\
\hline Institutional stability & $\begin{array}{l}0.501^{* *} \\
(0.146)\end{array}$ & $\begin{array}{l}0.461^{* *} \\
(0.158)\end{array}$ & $\begin{array}{l}0.342^{+} \\
(0.185)\end{array}$ \\
\hline Cultural diversity & $\begin{array}{l}0.276^{*} \\
(0.118)\end{array}$ & $\begin{array}{l}0.537^{* *} \\
(0.165)\end{array}$ & $\begin{array}{l}0.244^{*} \\
(0.105)\end{array}$ \\
\hline Constant & $\begin{array}{c}-0.275^{* *} \\
(0.093)\end{array}$ & $\begin{array}{c}-0.301^{* *} \\
(0.100)\end{array}$ & $\begin{array}{l}0.651^{* *} \\
(0.236)\end{array}$ \\
\hline$\rho$ & $\begin{array}{l}0.384^{* *} \\
(0.104)\end{array}$ & $\begin{array}{l}0.329^{* *} \\
(0.111)\end{array}$ & $\begin{array}{c}0.046 \\
(0.103)\end{array}$ \\
\hline Observations & 57 & 57 & 57 \\
\hline Div instrumented & $\mathrm{N}$ & $\mathrm{Y}$ & $\mathrm{Y}$ \\
\hline$A C D$ instrumented & $\mathrm{Y}$ & $\mathrm{Y}$ & Y \\
\hline Country fixed effects & $\mathrm{N}$ & $\mathrm{N}$ & $\mathrm{Y}$ \\
\hline \multicolumn{4}{|c|}{$\begin{array}{l}\text { The } 4 \text { NUTS1 regions in Greece are left out in the spatial } \\
\text { autoregressive model due to missing data in world distance } \\
\text { matrix. } \\
\text { Standard errors in parentheses. } \\
+{ }^{+} p<0.1,{ }^{*} p<0.05,{ }^{* *} p<0.01 \text {. }\end{array}$} \\
\hline
\end{tabular}


Table 6: A Subset of Attitudinal Responses

\begin{tabular}{lccc}
\hline \hline & Natives & Immigrants & \\
& mean & mean & t-test \\
\hline Most people can be trusted or you can't be too careful & 4.68 & 5.01 & $-0.33^{* * *}$ \\
Important to make own decisions and be free & 2.27 & 2.17 & $0.10^{* * *}$ \\
Important to help people and care for others' well-being & 2.27 & 2.15 & $0.12^{* * *}$ \\
Important to do what is told and follow rules & 3.01 & 3.02 & -0.01 \\
\hline Observations & 51617 & 4904 &
\end{tabular}

The table is made from ESS Round 4 using the whole sample. The immigrants here are defined as those who were not born in the country of residence.

Standard errors in parentheses.

${ }^{*} p<0.05,{ }^{* *} p<0.01,{ }^{* * *} p<0.001$. 
Appendix 


\begin{tabular}{|c|c|c|c|}
\hline & Natives & Immigrants & \\
\hline & Mean & Mean & t-test \\
\hline \multicolumn{4}{|c|}{ Media and Social Trust } \\
\hline TV watching, total time $(0-7)$ & 4.43 & 4.33 & $0.10^{* *}$ \\
\hline Radio listening, total time (0-7) & 2.79 & 2.48 & $0.31^{* * *}$ \\
\hline Newspaper reading, total time $(0-7)$ & 1.31 & 1.30 & 0.01 \\
\hline $\begin{array}{l}\text { Most people can be trusted } \\
\text { (0-10,10 denotes "high trust") }\end{array}$ & 4.68 & 5.02 & $-0.34^{* * *}$ \\
\hline Most of the time people helpful $(0-10)$ & 4.56 & 4.86 & $-0.30^{* * *}$ \\
\hline \multicolumn{4}{|c|}{ Politics } \\
\hline $\begin{array}{l}\text { How interested in politics } \\
(1-4,1 \text { denotes "very interested") }\end{array}$ & 2.64 & 2.59 & $0.05^{* * *}$ \\
\hline Trust in the country's parliament $(0-10)$ & 4.21 & 4.49 & $-0.29^{* * *}$ \\
\hline Trust in the legal system $(0-10)$ & 4.82 & 5.27 & $-0.45^{* * *}$ \\
\hline Trust in the police $(0-10)$ & 5.50 & 5.64 & $-0.15^{* * *}$ \\
\hline Trust in political parties $(0-10)$ & 3.33 & 3.72 & $-0.39^{* * *}$ \\
\hline Feel closer to a particular party $(1, \mathrm{yes} ; 2, \mathrm{no})$ & 1.50 & 1.58 & $-0.08^{* * *}$ \\
\hline How satisfied with life as a whole $(0-10)$ & 6.55 & 6.54 & 0.01 \\
\hline $\begin{array}{l}\text { Gays and lesbians free to live life } \\
\text { as they wish (1-5) }\end{array}$ & 2.45 & 2.52 & $-0.07^{* * *}$ \\
\hline $\begin{array}{l}\text { Allow many immigrants of different race/ethnic } \\
\text { group from majority (1-4) }\end{array}$ & 2.56 & 2.35 & $0.212^{* * *}$ \\
\hline $\begin{array}{l}\text { Immigration bad or good for country's economy } \\
(0-10,10 \text { denotes "good") }\end{array}$ & 4.76 & 5.82 & $-1.06^{* * *}$ \\
\hline $\begin{array}{l}\text { Country's cultural life enriched by immigrants } \\
(0-10,10 \text { denotes "agree strongly") }\end{array}$ & 5.30 & 6.29 & $-0.99^{* * *}$ \\
\hline
\end{tabular}

Subjective Well-Being, Social Exclusion, and Religion

\begin{tabular}{llll}
\hline How happy are you $(0-10)$ & 6.93 & 7.00 & $-0.07^{*}$ \\
\hline
\end{tabular}


How often socially meet with friends, relatives or colleagues

$4.85 \quad 4.72 \quad 0.127^{* * *}$

(1-7, 1 denotes "never")

Anyone with whom to discuss intimate and personal matters with

(1, yes; 2 , no)

$1.13 \quad 1.17-0.04^{* * *}$

Take part in social activities compared to others of same age

(1-5,5 denotes "much more than most")

$2.70 \quad 2.56 \quad 0.15^{* * *}$

How religious are you $(0-10)$

$4.87 \quad 5.13 \quad-0.25^{* * *}$

\section{Human Values}

\begin{tabular}{lccc}
\hline Important to be creative (1-6, 1 denotes "important") & 2.65 & 2.60 & $0.05^{*}$ \\
Important that people are treated equally (1-6) & 2.15 & 2.04 & $0.11^{* * *}$ \\
Important to try new and different things(1-6) & 3.00 & 2.93 & $0.07^{* *}$ \\
Important to follow rules (1-6) & 3.02 & 2.97 & 0.04 \\
Important to be humble and modest (1-6) & 2.76 & 2.60 & $0.16^{* * *}$ \\
Important to have a good time (1-6) & 2.99 & 2.94 & $0.05^{*}$ \\
Important to make own decisions (1-6) & 2.27 & 2.18 & $0.09^{* * *}$ \\
Important to help people and care for others(1-6) & 2.27 & 2.15 & $0.12^{* * *}$ \\
Important to behave properly (1-6) & 2.61 & 2.49 & $0.11^{* * *}$ \\
Important to get respect from others (1-6) & 3.10 & 2.90 & $0.20^{* * *}$ \\
Important to be loyal to friends (1-6) & 2.03 & 1.97 & $0.07^{* * *}$ \\
Important to follow traditions and customs (1-6) & 2.63 & 2.57 & $0.06^{* *}$ \\
\hline Observations & 52437 & 4107 & \\
\hline \hline
\end{tabular}

Source: ESS questionnaires. 